\title{
PROYECTO DE EXPLORACION GEOLÓGICAS MINERA DE MINERALES METÁLICOS DE LA ZONA DE PALCA Y PALQUILLA
}

Responsable : Ing. Zenón Sarmiento Mejia Miembros : Ing. Gualberto Tejada Bedoya Ing. Carlos Huisa Ccori

\section{RESUMEN}

El presente trabajo tiene sus orígenes en que por la zona de Palca y Palquilla, departamento de Tacna, se encuentran yacimientos principalmente de cobre para su exploración y explotación. Se fundamenta en el hecho de que el mineral de cobre existente en la zona, ya se en cancha o en yacimiento, tiene un valor comercial que hace muy interesante la exploración de la mencionada zona. Generalmente los yacimientos de la zona están defectuosamente explorados, esto hace que el proyecto sea viable.

\section{ABSTRACT}

This work has its origins in that area and Palquilla Palca, department of Tacna, is mainly copper deposits for exploration and exploitation. Is based on the fact that the copper ore in the area is already in court or field, it appears to have a commercial value that makes it very interesting exploration of the area.

\section{UBICACIONN}

La zona de afloramiento de cobre, plata y otros se encuentra ubicada a 73 kilómetros de la ciudad de Tacna, geológicamente en el flanco andino occidental, es la entidad topográfica que se extiende al norte y noreste de las pampas costaneras, es un territorio escabroso y muy disectado que se desarrolla entre 2000 y 5000 m.s.n.m.

El petitorio abarca una superficie de 100 hectáreas. El yacimiento "Canahura 1 de Palca" se ubica en la quebrada de Uchusuma y Cerro Chuluncane, cerca del antiguo pueblo de Bellavista en el distrito de Palca, provincia de Tacna, a 3900 m.s.n.m.

Se ubica en las siguientes coordenadas U.T.M :

$\begin{array}{ll}8034000 & 408000 \\ 8034000 & 409000 \\ 8033000 & 409000 \\ 8033000 & 408000\end{array}$

con una altitud aproximada de 3900 m.s.n.m.

\section{ACCESIBILIDAD}

La vía de acceso desde la ciudad de Tacna se realiza por la carretera parcialmente asfaltada Tacna (tramo de $45 \mathrm{~km}$ ), para continuar por la carretera afirmada a Palca, luego se ingresa por una trocha carrozable hasta un tramo de aproximadamente $3 \mathrm{~km}$ y se arriba al antiguo yacimiento de Canahura, actualmente denominado "Palca 1". Es accesible desde Tacna siguiendo esta ruta:

$$
\begin{array}{ll}
\text { Tacna - Palca - Cerro Pelado } & 70 \mathrm{~km} \\
\text { Desvío-Mina (trocha) } & 03 \mathrm{~km}
\end{array}
$$

\section{MÉTODO DE TRABAJO}

Después de un reconocimiento preliminar en la zona, se procedió a la ubicación e identificación de las labores antiguas. Para iniciar el programa de muestreo, se hizo un relacionamiento lito-estratigráfico del lugar, se procedio a realizar un mapeo geológico preliminar tomando como parte importante las estructuras.

\section{GEOMORFOLOGÍA}

Las unidades geomorfológicas de la zona denominada cuadrángulo de Palca, en donde el terreno más alto se encuentra en la parte nororiental de la zona y consiste en conos volcánicos (antiguos y modernos) que alcanzan una altura máxima de 5500 m.s.n.m.

Los elementos geomorfológicos son:

- La superficie Huaylillas.

- El Altiplano, con sus pampas extensas de depósitos fluvio-glaciares y sus volcanes del Plioceno y Cuaternario.

- Las terrazas de los valles de Caplina, Chero y Palca. 
La superficie Huaylillas está asociada con la Formación Huaylillas, que consiste de tres miembros distintos.

Al norte y NE de la zona está la unidad gemorfológica Altiplano, consiste en pampas extensas a una altura media entre 4,200 y 4,300 m.s.n.m. con algunos conos volcánicos que alcanzan entre 1,000 y 1,500 m de altitud, siendo los que forman la Cordillera del Barroso que es una cadena de volcanes con rumbo norte-sur, observándose que todos los volcanes tienen flancos cortados por quebradas hondas en forma de "U".

El flanco oriental de la Cordillera del Barroso tiene una cubierta de fluvio-glaciares y de pampa, los flancos occidentales bajan gradualmente hasta los $4,000 \mathrm{~m}$ sin mayor desarrollo de estos depósitos.

Hidrología:Este depósito tiene una diferencia respecto a las otras de la zona cerca del campamento y las labores: pasa por allí un riachuelo que posee agua todo el año $10-20$ litros por segundo.

Clima y Vegetación:El clima es templado a frío por su altitud, el periodo de lluvias se extiende de diciembre a marzo.

\section{GEOLOGIAA REGIONAL}

El área del presente trabajo forma parte de la cuenca andina externa en el sur del Perú cuyas caracteristicas de sedimentación marina mesozoica marcan tres etapas fundamentales a lo largo de su formación.

Las fuertes actividades tectónica originaron cambios de fases, traduciéndose en una secuencia de derrames volcánicos riolíticos, brechas de flujo, tobas sedimentarias y derrames lávicos (Formación Chocolate).

El flysh, con típicos sistemas de abanicos submarinos turbidíticos, compuesto de calizas fosiliferas con bancos de areniscas fosfatadas (Formación Pelado) y posteriormente de areniscas y carbonatos pelágicos, grupo Yura.

\section{CÁLCULO DEL MATERIAL}

El desmonte del mineral se encuentra en 42 canchas que se muestran en la tabla.

\begin{tabular}{|c|c|c|c|}
\hline CANCHA & $\begin{array}{c}\text { AREA ( } \\
\left.\mathrm{m}^{2}\right)\end{array}$ & $\begin{array}{l}\text { VOLUM } \\
\text { EN }\left(\mathrm{m}^{3}\right)\end{array}$ & $\begin{array}{c}\text { TONELAJE } \\
\text { (ton) }\end{array}$ \\
\hline Cancha 1 & 491,14 & 1473,42 & 3683,55 \\
\hline Cancha 2 & 57,72 & 173,16 & 432,90 \\
\hline Cancha 3 & 94,31 & 282,93 & 707,33 \\
\hline Cancha 4 & 29,94 & 59,88 & 149,70 \\
\hline Cancha 5 & 95,68 & 287,04 & 717,60 \\
\hline Cancha 6 & 603,23 & 1809,69 & 4524,23 \\
\hline Cancha 7 & 587,84 & 2351,36 & 5878,40 \\
\hline Cancha 8 & 146,56 & 439,68 & 1099,20 \\
\hline Cancha 9 & 697,90 & 2093,70 & 5234,25 \\
\hline Cancha 10 & 408,64 & 1634,56 & 4086,40 \\
\hline Cancha 11 & 278,17 & 834,51 & 2086,28 \\
\hline Cancha 12 & 26,84 & 53,68 & 134,20 \\
\hline Cancha 13 & 17,92 & 35,84 & 89,60 \\
\hline Cancha 14 & 890,39 & 2671,17 & 6677,93 \\
\hline Cancha 15 & 225,23 & 675,69 & 1689,23 \\
\hline Cancha 16 & 39,78 & 159,12 & 397,80 \\
\hline Cancha 17 & 182,27 & 729,08 & 1822,70 \\
\hline Cancha 18 & 1030,74 & 3092,22 & 7730,55 \\
\hline Cancha 19 & 123,78 & 495,12 & 1237,80 \\
\hline Cancha 20 & 69,02 & 276,08 & 690,20 \\
\hline Cancha 21 & 67,18 & 335,90 & 839,75 \\
\hline Cancha 22 & 192,21 & 384,42 & 961,05 \\
\hline Cancha 23 & 114,94 & 229,88 & 574,70 \\
\hline Cancha 24 & 959,08 & 2877,24 & 7193,10 \\
\hline Cancha 25 & 151,42 & 605,68 & 1514,20 \\
\hline Cancha 26 & 242,64 & 727,92 & 1819,80 \\
\hline Cancha 27 & 319,54 & 1597,70 & 3994,25 \\
\hline Cancha 28 & 242,02 & 968,08 & 2420,20 \\
\hline Cancha 29 & 65,92 & 197,76 & 494,40 \\
\hline Cancha 30 & 289,83 & 289,83 & 724,58 \\
\hline Cancha 31 & 55,04 & 275,20 & 688,00 \\
\hline Cancha 32 & 342,83 & 685,66 & 1714,15 \\
\hline Cancha 33 & 51,87 & 103,74 & 259,35 \\
\hline Cancha 34 & 36,49 & 145,96 & 364,90 \\
\hline Cancha 35 & 112,62 & 337,86 & 844,65 \\
\hline Cancha 36 & 16,72 & 50,16 & 125,40 \\
\hline Cancha 37 & 267,63 & 535,26 & 1338,15 \\
\hline Cancha 38 & 342,83 & 1371,32 & 3428,30 \\
\hline Cancha 39 & 134,95 & 404,85 & 1012,13 \\
\hline Cancha 40 & 87,03 & 261,09 & 652,73 \\
\hline Cancha 41 & 112,27 & 449,08 & 1122,70 \\
\hline Cancha 42 & 50,08 & 150,24 & 375,60 \\
\hline TOTAL & 10352,24 & 32612,76 & 81531,90 \\
\hline
\end{tabular}

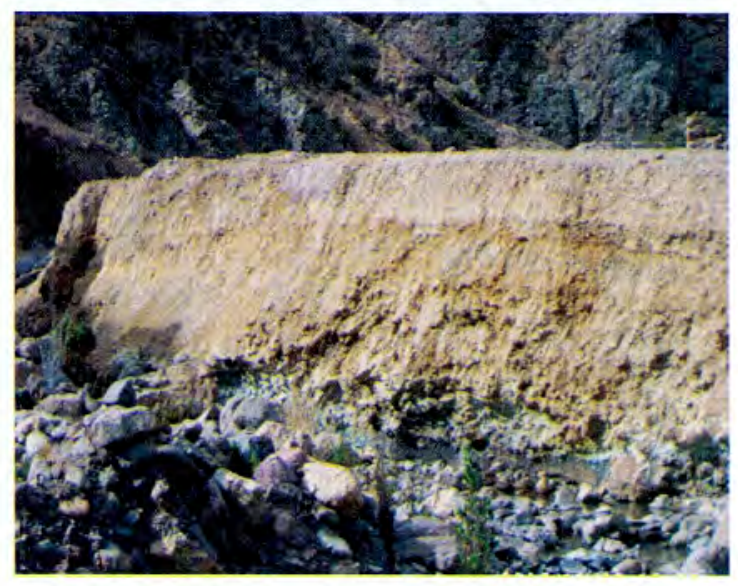

Material lixiviado por acción de la lluvia. 


\section{PROCESO DE EXPLOTACIÓN}

Luego de identificar la geología del yacimiento por medio de la exploración, en nuestro caso es el muestreo por canales, para cubicar la cantidad de mineral disponible en estos botaderos, se procede a seleccionar el método de explotación, forma de procesamiento del mineral y las operaciones de producción.

El método escogido será el de "transferencia", o sea el traslado de mineral de los stock a los pads preparados, ya que el mineral ya se encuentra triturado e intemperizado con una granulometria adecuada para aplicar el sistema de recuperación metalúrgica por lixiviación.

El proceso consiste en que por medio de un camión Volvo de 12 t y un cargador frontal de 1 yd3 acopiar todo el material de los botaderos hacia los pads.

PAD \#01: Los botaderos del 23 a 42 con un total de $30661,25 \mathrm{t} .=37,60 \%$

PAD \#02: Los botaderos del 01 a 22 con un total de $50870,65 \mathrm{t} .=62,4 \%, \quad 81582,15 \mathrm{t}$ $=100 \%$.

\section{a) equipo a utilizar para minado:}

- 01 Camión Volvo de $12 \mathrm{t}$

- 01 C. F. de 1 yd3

- 01 tractor D7

- 01 Equipos auxiliares

- 01 Equipos livianos

- 01 Grupo electrógeno

\section{b) Plan de producción:}

PAD \# 01:

PAD \#02:

Área :500m2

$800 \mathrm{~m} 2$

Cap. Proc : $30661,25 \mathrm{t}$

Pila : $2264,7 \mathrm{t}$

$50870,65 \mathrm{t}$

$2264,7 \mathrm{t}$

Tiempo :3 años

3 años

\section{PLANTA DE PROCESAMIENTO METALÚRGICO:}

El beneficio de los minerales oxidados que contiene Malaquita $\mathrm{Cu} \mathrm{CO} 3 . \mathrm{Cu}(\mathrm{OH}) 2$, brocantita CuSO4.3Cu $(\mathrm{OH}) 2$, crisocola $\mathrm{CuSiO} 3.2 \mathrm{H} 2 \mathrm{O}$ y otros como Ag y Au.

Se realizará mediante un proceso

Hidrometalúrgico que consta de las siguientes fases:

a) Circuito de Chancado: El mineral procedente de los botaderos antes descritos que contengan pedrones grandes,

superiores a 2" será triturado a base de combos, sobre una parrilla especial preparada con un macho de $20 \mathrm{lb}$.

b) Lixiviación en Cancha:Las canchas de lixiviación o "Pads" son áreas especiales preparadas en las quebradas o depresiones del terreno cuya superficie será imprimada e impermeabilizada con geomembranas resistentes a la erosión y el ácido como ser el HOPE $1 \mathrm{~mm}$. Se construirán dos canchas con un área total de $1300 \mathrm{~m} 2$.

\section{INVERSIONES Y COSTOS PARA RECUPERACION DE LOS DESMONTES MINERALIZADOS DEL YACIMIENTO CANAHURA 1.}

Flujo de Caja Económico:

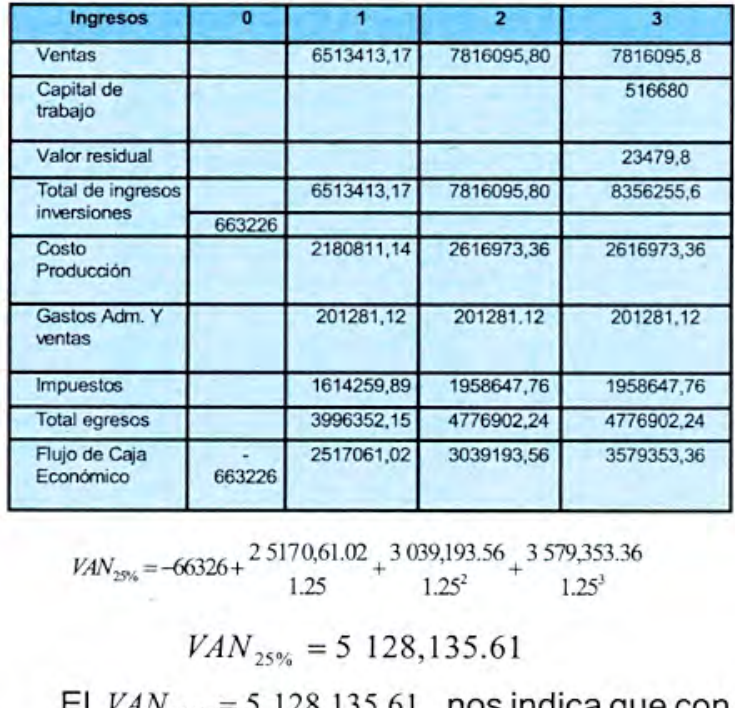

El $V A N_{25 \%}=5128,135,61$, nos indica que con una tasa de retorno de $25 \%$ anual tenemos un beneficio neto de 528 635,61 dólares americanos; además la recuperación de la inversión se realiza en solo 4 meses de la producción. Y genera trabajo directo para 15 personas. Estos resultados indican que es viable la recuperación de los desmontes de la mina Canahura 1 y al mismo tiempo soluciona los pasivos ambientales.

\section{CONCLUSIONES}

1.La zona de afloramiento consiste en una depresión, en donde se levanta un terreno de fuerte pendiente y de topografía dificil, consiste en una quebrada con un cauce de un riachuelo.

2.La mina Palca 1 tiene mineral en cancha que aproximadamente ofrece $81531,90 \mathrm{TM}$. Que desde el punto de vista ambiental, ofrecen serios problemas a la zona, por lo que se recomienda recuperar el mineral que todavía es rentable a precios actuales y simultá- 
neamente eliminar los residuos sólidos contaminantes.

3.La producción de este proyecto esta catalogada de la siguiente forma:

PAD\# 01

$\begin{array}{llll}\text { Área }: & 500 \mathrm{~m} 2 & 800 \mathrm{~m} 2 \\ \text { C P }: & 30661,25 \mathrm{t} & 50870,65 \mathrm{t} \\ \text { Pila : } & 852 \mathrm{t} & 1413 \mathrm{t}\end{array}$

4.Este estudio preliminar de inversiones y costos nos indica que con una inversión mínima obtenemos beneficios razonables.

5.La inversión en capital de trabajo en este estudio es superior a la inversión fija debido a que estos costos de producción son elevados como consecuencia de alquiler de equipos de carguío y transporte, además del alto costo de insumos.

6.Para calcular la rentabilidad del proyecto se ha supuesto mantener una tasa de descuento del costo ponderado de capital del $25 \%$ anual y se obtiene un

\section{VAN $25 \%=5128,135.61$}

\section{RECOMENDACIONES}

Un adecuado manejo de desmontes mineralizados, que fueron considerados como pasivo ambiental, en la actualidad puede convertirse en alternativas viables de explotación económica.

La inversión según este estudio se puede recuperar en menos de un año.

Este estudio nos permitirá dar una alternativa de solución en la recuperación de desmontes mineralizados existentes en varias minas abandonadas y de esta manera solucionar el pasivo ambiental minero.

\section{BIBLIOGRAFÍA}

Bateman Alan M. Yacimientos minerales de rendimiento económico.

Cornelius S., Hurlbut.Manual de Mineralogia, de Dana Ed. Reverte, 1974.

Corrales, C. Estratigrafia. Editorial Rueda, Madrid 1977.

Frederic H., Lahee. Geologia práctica.

Ediciones Omega, 1970.

Klaws, Stainmüller. Depósitos metálicos en el Perú, INGEMMET, 1999.

Kraus Hunt Romsdell, Mineralogía.McGrawHill.

Krumbein y Sloss. Estratigrafia $y$ sedimentación, Editorial Uthea.

Burta (1982). Aspectos generales de los y 45 acimientos en SKARN-Horward U.S.A.

Bustillo (1982). Manual de evaluación y diseño de explotación en mineria. Madrid.

Browner C.D (1972). Estability Investigation for Rock Slopes on Mininy Proyects VII.

Douglas R. Emery y otros (2000).1ra. edición.

Fundamentos de la Administración Financiera. Editorial Preutice Hall, México.

Varela V. Rodrigo (1993) Evaluación económica de proyectos. Editorial Norma, Bogotá. 